\title{
Más allá de la gubernamentalidad: políticas de colonización y desarrollo rural en el piedemonte caqueteño $(1960-1980)^{1}$
}

\author{
Sandra Patricia Martínez B. ${ }^{2}$ \\ Universidad del Valle, Santiago de Cali, Colombia ${ }^{3}$ \\ sandra.p.martinez@correounivalle.edu.co \\ Recibido: 20 de mayo de 2015 \\ Aceptado: 1 de octubre de 2015 \\ Disponible en línea: 9 de mayo de 2016
}

\footnotetext{
1 Artículo de investigación. El artículo presenta parte de los resultados del proyecto de investigación "La formación local del Estado en una región de frontera: el caso del piedemonte caqueteño (1960-1980)". Agradezco el apoyo financiero concedido por la Vicerrectoría de Investigaciones de la Universidad del Valle para la realización de este trabajo.

2 Doctora en Antropología Social de la Universidad Iberoamericana, campus Ciudad de México

3 Profesora de tiempo completo, Departamento de Ciencias Sociales
} 


\title{
Más allá de la gubernamentalidad: politicas de colonización y desarrollo rural en el piedemonte caqueteño (1960-1980)
}

\section{Resumen}

Las politicas públicas se inscriben dentro de formas de gubernamentalidad específicas en tanto se articulan a determinados proyectos de gobierno. Aunque estas políticas pueden tener una función instrumental en la legitimación de un proyecto de dominación estatal, su efectividad no es algo que pueda darse por sentado; ellas toman formas sociales dependiendo de los contextos particulares en los que son implementadas, así como de las disimiles lecturas e interpretaciones que tanto sus destinatarios como quienes las adelantan, hacen de las mismas. A la luz del estudio de caso de los programas de colonización y desarrollo rural ejecutados entre 1960 y 1980 por la Caja Agraria y el Incora en el piedemonte caqueteño, veremos cómo las prácticas desplegadas por los colonos y funcionarios implicados en la puesta en operación de estos programas pueden terminar subvirtiendo sus propósitos iniciales, imprimiéndoles de esta manera, giros inesperados.

Palabras clave: gubernamentalidad; políticas públicas; problematización; traducción técnica; categorización

\section{Beyond Governmentality: Colonization Policies and Rural Development in the Caquetá Foothill (1960-1980)}

\begin{abstract}
Public policies subscribe into specific governmentality forms, as long as they are linked to certain government projects. Although these policies may have an instrumental role in the legitimation of a state domination project, their effectivity cannot be taken for granted. They take social forms depending on the particular contexts where they are implemented, while also having different readings and interpretations made by those who make them and the ones the policies are made for. In the light of the case study of the colonization and rural development programs executed between 1960 and 1980 by the Caja Agraria and the Incora in the Caqueta Foothill, we will see how the practices used by the settlers and public officers involved in the implementation of these programs may end up subverting their initial purposes, making them take unexpected turns.
\end{abstract}

Keywords: governmentality; public policies; questioning; technical translation; categorization

\section{Mais para além da governamentalidade: politicas de colonização e desenvolvimento rural no sopé do monte em Caquetá (1960-1980)}

\section{Resumo}

As políticas públicas são abrangidas por formas de governamentalidade específicas ao mesmo tempo que articuladas a certos projetos de governo. Embora estas políticas puderem ter função instrumental na legitimação de um projeto de dominação estatal, sua efetividade não é algo que possa ser um dado adquirido; elas tomam formas sociais dependendo dos contextos particulares em que são implementadas, bem como as leituras diferentes e interpretações que tanto seus beneficiários como quem aplica, fazem delas. À luz do estudo de caso dos programas de colonização e desenvolvimento rural executados entre 1960 e 1980 pela Caja Agraria e Incora no sopé do monte caquetenho, vamos ver como é que as práticas desenvolvidas pelos colonos e funcionários envolvidos no comissionamento destes programas podem terminar subvertendo seus propósitos iniciais, imprimindo de esta maneira, viragens inesperadas.

Palavras-chave: governamentalidade; politicas públicas; problematização; tradução técnica; categorização 
El pensamiento foucaultiano se ha convertido en un punto de referencia clave para aquellos autores que se han aproximado desde una perspectiva crítica al mundo de las políticas públicas. La noción de gubernamentalidad, acuñada por el filósofo francés para develar el funcionamiento del gobierno moderno, ha servido de inspiración a los científicos sociales interesados en el examen de las complejas articulaciones que entrelazan autoridad, conocimiento y técnica para el direccionamiento de la conducta de los individuos. Dentro de este campo de estudios una de las líneas de análisis más fructífera ha sido el abordaje de las técnicas, instrumentos y programas que buscan regular y administrar la población a través de políticas como la ordenación del espacio urbano, la lucha contra la pobreza y la inseguridad, el manejo de la seguridad social y el riesgo, la regulación de la maternidad, la disminución del desempleo (Inda, 2005), el desarrollo rural, entre otras. Esta literatura se ha caracterizado por hacer énfasis en el rol instrumental que las políticas juegan en la regulación social, en la expansión del poder burocrático estatal y en la reproducción de las relaciones de dominación sobre las poblaciones a las cuales se dirigen, así como en el efecto conceptual e ideológico que ellas producen en la representación de los problemas sociales que, mediante el lenguaje objetivo y neutral de la ciencia, son estructurados en términos técnicos, siendo de esta manera despojados de su naturaleza política (Mosse, 2005/2012).

Ahora bien, aunque dicha perspectiva de análisis puede resultar provechosa para comprender el papel que estas politicas tienen en la legitimación de un proyecto global de dominación estatal, no lo es tanto a la hora de abordar empíricamente la relación entre las políticas y la práctica, toda vez que esta mirada tiende a dejar de lado las constelaciones específicas de actores, actividades e influencias que intervienen en su producción. Con esta idea en mente, en el presente artículo pretendemos demostrar cómo las racionalidades de gobierno, vehiculadas a través de políticas públicas específicas, nunca logran imponerse del todo, en tanto que los actores involucrados en su puesta en operación les imprimen giros inesperados.

En este marco, la pregunta por la manera como se ejerce gobierno en una región de frontera, situada en los márgenes espaciales y sociales 
de la nación, adquiere gran relevancia para entender cómo se despliegan dichas racionalidades en zonas donde la soberanía estatal es débil o prácticamente inexistente. Es el caso del Caquetá de mediados del siglo anterior, donde los procesos de articulación de la región a la vida nacional hasta esa parte, se habían limitado a su vinculación esporádica al mercado como proveedora de materias primas y mano de obra barata, o a su integración a la geopolítica de la guerra como sitio estratégico para ejercer el control de las fronteras. Solo hasta la década del cincuenta empieza a reconocerse en la expansión de la frontera interior hacia esta región, una posible salida a los conflictos agrarios que se vivían en el centro del país.

Las politicas de colonización dirigida y de desarrollo rural integral implementadas por la Caja de Crédito Agrario, Industrial y Minero (Caja Agraria) y el Instituto Colombiano de Reforma Agraria (Incora) en el piedemonte caqueteño, entre 1960 y 1980, se constituyen entonces en un terreno fértil para develar los límites en la implementación de la racionalidad de gobierno estatal. Es así como a la luz de este estudio de caso, veremos cómo los destinatarios de estos programas desarrollan estrategias creativas que muchas veces terminan subvirtiendo sus propósitos iniciales, al tiempo que los funcionarios a cargo de su implementación suelen anteponer el cumplimiento de unas metas a la eficacia de los programas en la resolución de las necesidades de sus beneficiarios, trayendo consigo efectos inesperados.

En el primer apartado presentaremos una breve discusión sobre la noción de gubernamentalidad y los límites que esta racionalidad de gobierno supone en la dirección de la conducta de los individuos. En una segunda sección abordaremos el contexto nacional en el que surgieron las políticas de colonización y desarrollo rural, así como el rol que la Caja Agraria y el Incora jugaron dentro del proyecto de consolidación del orden estatal. En los tres acápites siguientes veremos el despliegue de estas políticas en la zona de estudio, mostrando las prácticas a través de las cuales se hicieron efectivas, pero también la manera como sus objetivos se vieron socavados por los distintos actores implicados en su operación. Cerraremos el artículo con algunas reflexiones finales. 
Teniendo en cuenta que la región piemontana abarca una gran extensión, decidimos focalizar nuestra atención en los frentes de colonización establecidos por la Caja Agraria en la zona a finales de los años cincuenta: Maguaré (municipio de El Doncello), La Mono (municipio de Belén de los Andaquíes) y Valparaíso, ubicado en el municipio del mismo nombre (Ver Mapa 1). Sin embargo, esta delimitación de la zona de estudio no excluyó la posibilidad de aproximarnos a la dinámica de estos programas en otras localidades, dado el acceso que tuvimos a algunos colonos que se asentaron en municipios distintos a los centros pioneros de la colonización dirigida, así como a funcionarios que participaron en la operación de dichos programas en zonas diferentes a los frentes de colonización.

Para la reconstrucción de estas políticas llevamos a cabo la revisión documental de distintas fuentes primarias y secundarias, asi como la recolección de información en la zona de estudio, a través de la realización de entrevistas en profundidad (en forma individual y grupal) a los beneficiarios de los programas y a los ex funcionarios del Incora que estuvieron a cargo de ellos, entrevistas que fueron efectuadas en distintas temporadas de trabajo de campo desarrolladas entre marzo de 2013 y enero de 2015.

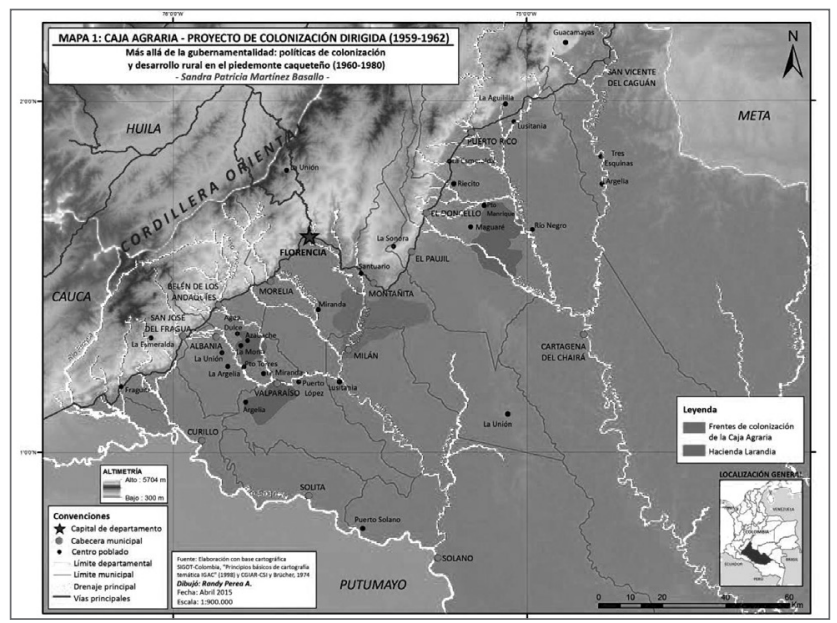

Mapa 1. Caja Agraria Proyecto de Colonización Dirigida (1959-1962)

Fuente: Elaboración propia con base cartográfica SIGOT- Colombia, IGAC (1998) y Brücher (1974) 


\section{La gubernamentalidad y sus limites}

En una de sus célebres clases en el Collège de France, Foucault (2006) señalaba cómo la modernidad asiste a un proceso creciente de gubernamentalización del Estado. Aunque la preocupación por el arte de gobernar empieza a expresarse en el siglo XVI, no fue sino hasta finales del XVIII que este alcanzó su amplitud y consistencia. La aparición del problema de la población como un campo de intervención y de la economía como un dominio específico de la realidad, apoyadas en el desarrollo de la estadística como saber técnico que posibilitó la cuantificación de las regularidades propias de la población, permitieron que la ciencia política lograra autonomizarse de la soberanía y de la familia como modelos de buen gobierno.

Según el autor, este proceso dio lugar a la configuración de una racionalidad gubernamental específica, que tiene en el bienestar de la población, su blanco principal, en la economía política, su primordial forma de saber, y en los dispositivos de seguridad, su instrumento por excelencia (Foucault, 2006). Distinta de la disciplina, que persigue la sujeción de los individuos mediante el control minucioso de las operaciones del cuerpo, la gubernamentalidad consiste en una forma de poder positivo que, mediante un conjunto de instituciones, procedimientos, cálculos y tácticas, actúa sobre y a través de la agencia y subjetividad de los individuos, como sujetos racionales y éticamente libres. En tal sentido, se dirige a potenciar la capacidad de estos últimos para convertirse en individuos autónomos y responsables que puedan cuidar de sí mismos, ocuparse de su propio bienestar y ser auto-gobernables (Shore y Wright, 1997).

No obstante, el mismo Foucault reconoce que el ejercicio de esta racionalidad de gobierno supone unos límites. El hecho de tener que lidiar con individuos cuyos valores e intereses pueden llegar a ser tan diversos, produce efectos imprevisibles, cuando no estrategias de resistencia por parte de los sujetos a los que se dirige. Este es precisamente el punto de partida de autores como James Ferguson (1994) quien, a la luz del estudio de caso de un proyecto de desarrollo rural implementado en Lesotho, analiza los efectos colaterales de las intervenciones 
burocráticas y el rol instrumental que estas juegan en el ejercicio del poder estatal. El autor demuestra cómo los proyectos de desarrollo no solamente son funcionales a la expansión del poder burocrático estatal, sino que además contribuyen a crear una representación despolitizante de la vida social, definiendo los problemas sociales como asuntos eminentemente 'técnicos' y ofreciendo soluciones igualmente 'técnicas' al sufrimiento de los pobres. Es en este sentido que califica a la industria del desarrollo como una máquina anti-política.

En la misma dirección, Shore (2010) sostiene que las políticas públicas normalmente tienen efectos que sobrepasan los propósitos fijados al inicio de la intervención. Apartándose de la consideración de estas políticas como procesos lineales, cuya puesta en operación supone una secuencia lógica de eventos que empiezan con su diseño y terminan con su ejecución, el autor plantea cuán fragoso puede ser el camino que estas recorren en su proceso de implementación. De ahí la necesidad de revalorar el supuesto según el cual los fracasos en la ejecución de las políticas pueden explicarse en virtud de un diseño erróneo de aquellas, de lo que se sigue que una adecuada formulación de estas políticas garantiza en sí misma su éxito. Si bien este factor incide en los resultados obtenidos, no explica del todo el rumbo que pueden llegar a tomar las politicas públicas que tienen 'vidas sociales' propias, cuya trayectoria puede seguirse a partir de la reconstrucción de las dinámicas que rodean su interpretación: "Una vez creadas, las políticas entran en una compleja red de relaciones con varios agentes, actores e instituciones, tinglado que puede a menudo generar consecuencias imprevistas e inesperadas" (Shore, 2010, p.36).

Además de impredecibles, el autor, esta vez con Susan Wright, plantea que las politicas públicas pueden calificarse de instrumentales en tanto que no solo se constituyen en herramientas de intervención para la administración y regulación de la sociedad sino que además legitiman las decisiones tomadas por los sectores que ostentan posiciones de autoridad. Sin embargo, esta voluntad de poder no es manifiesta sino que se esconde tras el velo del lenguaje pretendidamente objetivo y neutral en el que suelen expresarse las políticas, cuyos discursos de eficiencia y racionalidad sirven al propósito de presentarlas 
como la solución 'natural' a los problemas sociales. Son en definitiva, tecnologías politicas, que "reformulan un problema político en el lenguaje neutral de la ciencia" (Shore y Wright, 1997, p.31).

Siguiendo esta línea de análisis, Gupta (2012) se interesa en la comprensión de los factores que han posibilitado la persistencia de la extrema pobreza en la India pese a la ingente cantidad de recursos que se han invertido para contrarrestarla, encontrando en la manera como se despliegan las prácticas estatales una posible explicación de este fenómeno. Es decir, aunque los pobres en la India han sido incluidos en los proyectos nacionales de desarrollo, los propósitos de ayudar a este sector de la población se ven subvertidos por los procedimientos de las burocracias que, al anteponer el cumplimiento de unos objetivos al logro del bienestar de la población, terminan produciendo resultados arbitrarios. Retomando a Herzfeld, el autor caracteriza a las burocracias como 'máquinas productoras de indiferencia', pues aunque sus intervenciones pueden estar cargadas de buenas intenciones, el problema reside en cómo los procedimientos desplegados por ellas impiden que los servicios estatales les lleguen a los pobres.

Pese a la relevancia de una perspectiva crítica sobre el funcionamiento de las instituciones del desarrollo, algunos autores advierten que la consideración de las políticas agenciadas por estas instituciones como dispositivos de legitimación y ocultamiento de determinadas relaciones de poder termina ignorando la multiplicidad de actores, perspectivas e intereses involucrados en su implementación, así como la relación entre estas políticas y la práctica. En tal sentido, Mosse (2005/2012) plantea que solo a partir del reconocimiento de la capacidad de agencia de los actores implicados en el mundo de las políticas es posible superar la mirada dicotómica de estos como víctimas o victimarios, así como justipreciar las diversas motivaciones que animan sus acciones. Coincidiendo con este argumento, Li (2007) sostiene que no siempre quienes ejecutan los programas apoyan los intereses de los sectores dominantes y que el efecto despolitizante de las intervenciones de desarrollo no es algo que pueda darse por sentado. Estos llamados de atención no pueden ser desestimados a la hora de aproximarse al estudio de las politicas implementadas por la Caja Agraria 
y el Incora en el piedemonte caqueteño, que si bien cumplieron un rol instrumental en la consolidación del orden estatal en esta región, en su seno alojaron toda suerte de intereses e ideales, tal y como tendremos oportunidad de observar a continuación.

\section{Reforma agraria y colonización: el proceso de avance estatal en la frontera}

Como es ampliamente conocido, entre 1946 y 1966, el país se vio abocado a uno de los capítulos más difíciles de su historia recordado como el periodo de La Violencia. Además del desbordamiento de las contradicciones políticas y de la incapacidad del gobierno para regularlas, este fenómeno develó el profundo estancamiento en el que se encontraba sumergido el agro. La política de reforma agraria instaurada durante los primeros años del Frente Nacional surgió como una respuesta a esta crítica situación, pero la oposición de los grandes terratenientes, quienes recurrieron a todo tipo de artificios para evadir, o por lo menos retardar la aplicación de las medidas reformistas que afectaban sus intereses, dieron al traste con esta política.

Mientras la línea reformista perdía terreno, los argumentos a favor de la colonización de las tierras baldías de la nación cobraban fuerza. Sin comprometer la estructura agraria vigente, la ocupación de estas tierras podría impulsar la producción agropecuaria nacional a través de la incorporación de extensos territorios a la economía de mercado, además de constituirse en una alternativa de empleo para los campesinos expulsados por La Violencia, que día a día llegaban a las ciudades (Marsh, 1983). En el plano político la ocupación de las áreas de frontera representó la posibilidad de extender la soberanía estatal a zonas que, como el Caquetá, adolecían de una precaria presencia del Estado.

Para el logro de este propósito el gobierno nacional dirigió sus acciones al fortalecimiento del aparato burocrático a cargo de la atención de la población rural. De ahí que en el periodo comprendido entre 1960 y 1980, las entidades agrarias gozaron de un auge sin precedentes. La 
Caja Agraria llegó a convertirse en la corporación bancaria más grande del país. Aunque sus labores se enfocaron en la provisión de microcréditos a los pequeños y medianos productores, esta función devino cardinal dentro del esfuerzo gubernamental de pacificar y extender la legitimidad estatal hacia las áreas rurales, además de sujetar a las poblaciones rurales a un control burocrático directo por parte de los funcionarios estatales y de integrarlas a los mercados capitalistas de tierra y mercancías agrícolas (Herron, 2003).

Esta estrategia de gobierno estuvo acompañada de la implementación de diversos programas encaminados a la ampliación de la frontera agrícola y al poblamiento de los entonces llamados territorios nacionales. Fue así como en 1959 la Caja Agraria y la Oficina Nacional de Rehabilitación, encargada de la atención de la población afectada por La Violencia, firmaron un convenio para el establecimiento de colonias agrícolas en distintas regiones del país (Artunduaga, 1984; Jaramillo, 1989). Una de las zonas focalizadas para llevar a cabo estas acciones fue el piedemonte caqueteño, donde ese mismo año la Caja Agraria inició un programa de colonización dirigida.

Al igual que la Caja, el Incora jugó un papel central dentro del proyecto de consolidación estatal en las regiones de frontera. Creado mediante la Ley 135 de 1961 para administrar el proceso de adjudicación de los baldíos nacionales, desde sus inicios el Instituto se vinculó a la estrategia de pacificación adelantada por el Frente Nacional dirigiendo sus primeras acciones a la rehabilitación de las zonas que habían sufrido con mayor rigor el impacto de La Violencia (Galli, 1978). De manera consecuente con la ideología modernizadora que regía la política agropecuaria nacional, los programas del Incora se encaminaron al incremento de los niveles de productividad en el sector, además de ejercer un control centralizado de la administración de las fincas (Howard, 1976).

Ahora bien, aunque es posible identificar algunos rasgos generales en el modus operandi del Incora, es importante señalar que la naturaleza de su intervención varió en función de los contextos particulares en los que tuvo lugar. Por un lado, los programas implementados por 
el Instituto en el Caquetá no tuvieron como fin último el aumento de la productividad sino el desarrollo integral de los colonos. Por el otro, aunque el papel de las instituciones agrarias en la extensión del dominio estatal hacia las zonas de frontera resulta innegable, al estudiar empíricamente el desarrollo de sus programas en regiones especificas se descubre la necesidad de matizar el rol instrumental que estas juegan en la reproducción de las relaciones de poder, así como la mirada de estas instituciones como entidades monoliticas que operan bajo un criterio de acción unificada. En el caso del Incora la mayoría de sus funcionarios llegó a implicarse profundamente en la vida de los colonos, además de asumir un firme compromiso con las tareas que le fueron encomendadas, tal y como tendremos oportunidad de constatar en lo que sigue.

\section{Intervención técnica versus compromiso: dimensiones de las prácticas de gobierno}

El análisis de las prácticas que anteceden la puesta en operación de los programas gubernamentales puede resultar iluminador sobre la manera como estos llegan a hacerse efectivos. Según Li (2007), para traducir la voluntad de mejorar el destino de las poblaciones, implícita en toda racionalidad de gobierno, los programas de desarrollo se valen de dos estrategias. La primera consiste en la problematización, es decir la identificación de las necesidades o deficiencias que han de ser cubiertas por dichos programas y de las soluciones correspondientes. La segunda, en un ejercicio de traducción técnica a través del cual se produce la caracterización del campo a ser intervenido como un campo inteligible y claramente delimitado. Teniendo en cuenta que estas operaciones de diagnóstico y prescripción son efectuadas por expertos que han sido entrenados para estructurar problemas y soluciones en términos técnicos, al ser traducidos de esta manera, los asuntos de orden político como el acceso a la tierra y los recursos, el empleo y los ingresos, o la pobreza misma, son descontextualizados de la estructura de relaciones sociales y económicas en la que tienen lugar. Así, al ofrecer explicaciones reduccionistas de dichos problemas, esta doble 
estrategia de problematización y traducción técnica termina teniendo efectos despolitizadores en la representación de la vida social.

En un sentido importante, las políticas agrarias desplegadas por la Caja Agraria y el Incora en el Caquetá pueden leerse como el resultado de estas prácticas. En lo que tiene que ver con el programa de colonización dirigida adelantado por la Caja en la región, es clara la manera como se produce este ejercicio de traducción de problemas políticos al lenguaje neutral de la intervención técnica. Enfocado en los campesinos damnificados por La Violencia, este programa implicó la selección y traslado de las familias desde sus lugares de origen hacia los frentes de colonización establecidos por la entidad en la zona.

En un primer momento, dichas familias eran dotadas de una parcela y de un crédito de instalación y vivienda, el cual les era entregado por cuotas para sufragar sus gastos de subsistencia mientras que las fincas empezaban a producir. Posteriormente se procedía a la adjudicación de las parcelas y a la asignación de créditos agropecuarios con los cuales los colonos pudieran adquirir los semovientes, herramientas e insumos agrícolas necesarios para iniciar la producción. De esta manera los campesinos expulsados por La Violencia o que habían sido víctimas del despojo territorial a causa de la inequitativa distribución de la tierra en el interior del país o de la progresiva mecanización de la agricultura, se convertían en colonos sujetos de intervención burocrática; una intervención dirigida a resolver en el plano técnico a través de la titulación de tierras, la asistencia técnica y la capacitación, problemas de orden político como la concentración de la tierra o la crisis de legitimidad que atravesaba el Estado en ese momento.

Conscientes de ello, a finales de 1960 doscientos usuarios del programa de colonización dirigida en el Caquetá enviaron un memorial a la Cámara de Representantes en el que denunciaron las múltiples fallas asociadas a la implementación de este programa, además de plantear serios cuestionamientos a la política oficial de colonización por considerar que bajo esta política se estaba enviando a los campesinos a tierras marginales, de baja calidad, carentes de infraestructura y de 
servicios, mientras que las mejores tierras permanecian reservadas a las clases en el poder:

Mientras las tierras de las zonas vitales del país permanecen abandonadas, nuestro gobierno está enganchando los más vigorosos trabajadores del campo que se presentan a pedir tierra, respondiendo al llamado oficial, y los deporta a colonias de donde no podrán volver [...] buscando siempre zonas marginales que los negociantes de tierra no desean, zonas sin suelo vegetal, con excesiva lluviosidad, sujetas a inundaciones y sequías, sin vías de salida, sin mercados y $\sin$ servicios $[\ldots]$.

Con gran pompa se hace el enganche, se le abre un crédito por cinco mil pesos a cada jefe de familia, pero además de los altos intereses, éste [sic] debe pagar todo [...] Todo este crédito se acaba en cinco meses. La primera cosecha no se coge porque no hay suelo y si se la cogiera se perdería, porque no hay cómo sacarla, y el colono se queda sin con qué vivir de ahí en adelante, pero la ilusión de ser propietario de un monte de cincuenta hectáreas y el miedo de volver al centro, enfermo sin tener a dónde llegar, lo hace demorar la salida hasta ser demasiado tarde [...].

Colonización de tierras baldias con métodos rudimentarios y demagogia de masas, no es reforma agraria, ni a las buenas ni a las malas (E1 Espectador, 1960).

Algo similar sucedió con los programas adelantados por el Incora que a pesar de apostarle a una estrategia de desarrollo rural integral para la región, siguió privilegiando una orientación tecnocrática en la definición de los problemas a intervenir y en el planteamiento de posibles soluciones a dichos problemas. A mediados de 1962 el Incora suscribió un acuerdo con la Caja Agraria, mediante el cual se hizo cargo del programa adelantado por esta entidad en el Caquetá. Distanciándose del enfoque del programa hacia la colonización dirigida, el Instituto decidió reorientar sus politicas hacia el apoyo a los colonos que se habian trasladado por su propia iniciativa a la zona. Fue así como se dio inicio a la intervención del Incora en el Caquetá 
que, con el apoyo financiero de la Agencia de los Estados Unidos para el Desarrollo (Usaid) y del Banco Mundial ${ }^{4}$, dirigió sus acciones a la consolidación del proceso de asentamiento de los colonos en la región a través de la titulación de tierras baldías, provisión de créditos, prestación de asistencia técnica, construcción de vías de comunicación, escuelas y puestos de salud y ejecución de programas de desarrollo social. De nuevo los problemas de pobreza y desempleo rural, así como la incapacidad del gobierno para regular los conflictos sociales, son desnudados de su naturaleza política para ser traducidos al lenguaje objetivo y racional de la intervención técnica.

A estas dos estrategias -problematización y traducción técnica-habría que agregar una tercera consistente en la construcción de nuevas categorías de sujetos. Volviendo a la noción foucaultiana de gubernamentalidad entendida como aquella racionalidad de gobierno que actúa sobre las acciones de los individuos mediante un poder productivo dirigido a la creación de subjetividades (Foucault, 2006; Li, 2007), podemos señalar el papel que las politicas públicas juegan en el modelamiento de las identidades de individuos y grupos específicos, los cuales son clasificados y categorizados de acuerdo con diferentes criterios de clase, raza, género, etnicidad, edad, ciudadanía, estado civil, religión, ocupación, entre muchos otros (Shore y Wright, 1997). En el caso que nos ocupa, esta estrategia se vio reflejada en la categorización de los colonos como sujetos de intervención. Fue así como en el desarrollo de sus programas la Caja Agraria y el Incora se ciñeron a una tipología de colonos, según la cual estos podían clasificarse en dos tipos: 'espontáneos', es decir aquellos que por su propia cuenta y riesgo decidieron migrar hacia estas regiones motivados por la búsqueda de mejores condiciones de vida, o bien, huyendo de la violencia que asolaba sus lugares de origen y 'dirigidos', o sea quienes fueron asistidos por el gobierno en su proceso de migración y asentamiento en las regiones de frontera.

Estos principios de clasificación de la población se hicieron sentir en el trabajo cotidiano de los funcionarios a cargo de la implementación

4 Los proyectos desarrollados por el Incora durante este periodo fueron: Proyecto Caquetá 1 (19631971), financiado por Usaid, y Proyecto de Colonización del Caquetá, el cual abarcó dos fases: la primera entre 1971 y 1975 y la segunda, desde 1976 hasta 1980. Para la realización de este segundo proyecto el Banco Mundial le otorgó sendos créditos al gobierno colombiano. 
de dichos programas, quienes coinciden en señalar una clara distinción entre los colonos dirigidos y los espontáneos. En su opinión, el factor motivacional incidió directamente en la actitud de unos y otros hacia los programas que se adelantaban. Mientras que los primeros llegaron a la zona de manera inducida bajo la tutela de la Caja Agraria y en su mayoria sin contar con un conocimiento y experiencia previos de las labores agrícolas, los colonos espontáneos migraron motivados por el interés de hacerse a una nueva vida en estas tierras y por lo tanto, dispuestos a sortear las vicisitudes que se les pudieran presentar. Sin ningún apego a la tierra y al trabajo en el campo, ante la primera dificultad que se les presentaba, muchos colonos dirigidos decidieron regresarse a sus lugares de origen, caso contrario al de los espontáneos quienes, según los funcionarios, tuvieron un grado de permanencia mucho mayor en la región. Eusebio ${ }^{5}$, vinculado al Incora por un periodo de veinte años, describe de la siguiente manera la diferencia entre estas categorías de colonos:

El colono dirigido fue un colono casi que traído, traído sin calificarlo, es decir, sin mirar su vocación, no se miraba si era un campesino, si tenía extracción campesina, si era un agricultor, si tenía vocación de agricultor o ganadero, se traía la gente por ocupar tierras, porque ya había una parcelación distribuida por el Estado y dentro de esa parcelación había que ir colocando gente a que ocupara, mientras que el colono espontáneo venía y buscaba su tierra porque le nacía trabajar con eso, entonces daba más resultado el colono espontáneo que el dirigido, el colono dirigido fue mucho el que abandonó esas parcelas, les dieron las ayudas por La Caja Agraria y esas ayudas prácticamente las perdieron porque no tenían ese espíritu de ser campesinos, de trabajar la tierra y sacarla adelante. (Eusebio, entrevista, El Paujil, 15 de enero de 2015)

Hasta aquí hemos subrayado el efecto despolitizador de los programas de desarrollo que a través de esta doble estrategia de problematización y traducción, así como de la categorización de los individuos como sujetos de intervención, termina despojando los problemas de su

Con el fin de proteger la identidad de los entrevistados utilizamos nombres de pila ficticios para referirnos a ellos. 
carácter político para traducirlos al lenguaje neutral de la intervención técnica. No obstante, como señalamos antes, es necesario complejizar la mirada de estos programas para considerar la diversidad de actores y de intereses que intervienen en sus procesos de formulación e implementación. Solo de esta manera es posible reconocer el hecho de que no todos los actores implicados en ellos tienen el propósito de apoyar la dominación de unos grupos sobre otros, o de que incluso en aquellos proyectos que intentan imponer 'el desarrollo' de manera unilateral y excluyente, haya quienes realmente crean que esta sea la alternativa más adecuada. Como acertadamente advierte Mosse (2005/2012:

Señalar que las actividades de desarrollo sirven a ciertos intereses o que tienen ciertos efectos políticos no es lo mismo que explicar las motivaciones y los significados de las personas involucradas, o poner en duda su ética. El efecto de una cosa no explica sus propiedades. (p.277)

En lo que se refiere a nuestro estudio de caso, los testimonios de los ex funcionarios entrevistados son reveladores de su convicción en los programas ejecutados por el Incora como la mejor manera de asegurarle unas condiciones de vida digna a los colonos, así como de su compromiso con las diferentes tareas que les eran encomendadas y que ellos califican como la expresión de una 'mística' de trabajo. Sirvámonos de las palabras de Pablo, quien trabajó en el Instituto 25 años, para ilustrar este punto:

Realmente el Instituto era como una familia [...] y había un sentido de pertenencia muy grande con la entidad, un sentido de compromiso donde cada quien tenía claro lo que le tocaba hacer [...] era un trabajo bastante fuerte, pero había una mística muy grande [...] (Pablo, entrevista, Florencia, 18 de julio de 2013) 


\section{"La Caja Agraria nos dejó a la deriva"6: estrategias de resistencia de los colonos frente a las políticas públicas}

Hemos visto que el gobierno consiste en aquella modalidad de acción que se dirige a la conducción de la conducta de los individuos con respecto a fines específicos (Foucault, 2001). Ahora bien, siempre cabe la posibilidad de que los receptores de estas acciones actúen de otra manera. He aquí uno de los límites de la gubernamentalidad, dado por la misma población que constituye su objeto. Es decir que no podemos asumir de antemano que en todos los casos las racionalidades de gobierno logran imponerse. Estas toman diversas formas sociales dependiendo de los contextos en los que tienen lugar, así como de las múltiples lecturas que los individuos hacen de ellas de acuerdo con sus propias lógicas, intereses y necesidades.

Para entender el funcionamiento de estas racionalidades de gobierno, es preciso detenerse en las tecnologías políticas a través de las cuales operan. Ello nos conduce al análisis de las políticas públicas y de la manera como estas son recibidas y experimentadas por los sujetos a los cuales se dirigen (Shore y Wright, 1997). Coincidiendo con Agudo (2011) podemos decir que los destinatarios de las politicas son al mismo tiempo, objetos y agentes de ellas, en tanto que mediante la aplicación de sus propias reglas y la elaboración de sus interpretaciones, estos actores pueden terminar afirmando o socavando los objetivos de dichos programas, dándoles de esta manera giros inesperados.

En el caso que nos ocupa encontramos colonos que cuestionan abiertamente estos programas, como también quienes los utilizan para su beneficio personal en menoscabo de los propósitos oficiales, o quienes muestran una conformidad fingida hacia ellos mientras que al mismo tiempo evaden sus disposiciones. Así, al interrogar a los beneficiarios del programa de colonización de la Caja Agraria, sus voces son unánimes en señalar el fracaso del mismo toda vez que la gran mayoría de los colonos dirigidos abandonó las parcelas que les fueron asignadas

6 Palabras de Jesús María, beneficiario del programa de colonización dirigida, en entrevista realizada el 29 de marzo de 2013 en Maguaré. 
al poco tiempo de haberse trasladado a la zona. Jesús María que hizo parte de este programa en Maguaré, expresa sin ambages su inconformidad hacia la gestión de esta entidad:

La Caja Agraria nos dejó cinco años a la deriva, porque vinimos 2.500 colonos, fue los que vinimos, y no quedamos sino como unos 100 , los otros se fueron porque sin crédito, sin nada, sin nada con qué trabajar, ni nada, eso daban botado por lo que le dieran, si le daban en ese tiempo $\$ 10, \$ 20$ por la parcela, por eso vendian la gente. (Jesús María, entrevista, Maguaré, 29 de marzo de 2013)

Al margen de los factores que condujeron al fracaso en la consolidación de las colonias agrícolas, de los cuales nos ocuparemos con cierto detalle en el siguiente apartado, lo cierto es que un gran número de campesinos, una vez logró hacerse a las parcelas y a los créditos ofrecidos por la Caja Agraria, incumplió los compromisos adquiridos con la entidad. Fue así como muchos de ellos vendieron los lotes incluso antes de habérseles adjudicado en propiedad, mientras que otros los abandonaron y migraron hacia sus lugares de origen o en busca de nuevas tierras en las áreas aún no colonizadas. Asimismo, son frecuentes los relatos acerca del despilfarro de los recursos o de su utilización para fines distintos a los establecidos en los planes de crédito.

Este tipo de situaciones también se presentó entre los beneficiarios de los programas del Incora, quienes desplegaron distintas estrategias de resistencia a las disposiciones oficiales. El testimonio de algunos colonos muestra de qué manera estos lograban evadir dichas disposiciones sin perder los beneficios que estos proyectos podian representarles. Tal vez el caso más ilustrativo sea el del programa de fomento de caucho y palma aceitera implementado por el Instituto en la región. Por tratarse de cultivos de tardío rendimiento, estos productos requieren de un periodo de cuatro a siete años para entrar en fase de aprovechamiento. En un contexto en el que el aseguramiento de las fuentes de ingreso era inminente, cultivos como estos resultaban poco atractivos para los colonos, por lo que el Incora decidió condicionar la entrega de créditos a la destinación de una parte de la parcela a su siembra. Con la expectativa de obtener el crédito, muchos colonos 
accedieron a plantarlos, pero al no verse beneficiados en el corto plazo, terminaron tumbándolos para darle otra destinación a las tierras. Refiriéndose al programa de fomento cauchero, Mariela, lideresa de la comunidad indígena de Nasa Kiwe, relata lo siguiente:

Entonces se crean unos créditos que se llaman créditos supervisados [...] entonces era obligación de las personas sembrar las dos hectáreas de caucho. Cuando eso, los dos primeros beneficiarios de acá de la comunidad, fueron Antonio Guejia y Aurelio [...] y resulta que por ejemplo Antonio [...] creo que no aceptó sembrar las dos hectáreas, don Aurelio tampoco quería, pero al fin cuando los vinieron a supervisar, como eso había un señor que supervisaba esos créditos, él sí entonces lo sembró al otro lado de la casa, al otro lado de la quebrada, ese caucho se le creció bonito, y luego él lo mandó a rozar, es que él no quería eso. (Mariela, entrevista, Nasa Kiwe, 25 de marzo de 2013)

Estos ejemplos revelan cómo las racionalidades de gobierno, vehiculadas a través de políticas públicas específicas, son producidas socialmente, por lo que su efectividad en la dirección de la conducta de los individuos no es algo que pueda darse por sentado. Los destinatarios de estas politicas no son agentes pasivos, ellos las interpelan, reinterpretan y resignifican de acuerdo con sus valores e intereses particulares. Algunas veces acatan las reglas del juego, mientras que otras, son refractarios a ellas, haciendo de estas politicas procesos totalmente imprevisibles, como tendremos oportunidad de observar a continuación.

\section{"Estábamos experimentando ambos, la entidad y el campesino"7: efectos no intencionados de las políticas públicas}

En un apartado anterior señalábamos que uno de los límites en el ejercicio de la gubernamentalidad reside en el hecho de que esta normalmente no alcanza lo que se propone. Según Li (2007) esto se puede

Palabras de Roberto, ex funcionario del Incora, para referirse al carácter experimental de los programas de fomento al caucho y la palma aceitera implementados por el Incora en el Caquetá. Entrevista realizada en Florencia el 18 de julio de 2013. 
explicar en virtud de las limitaciones inherentes a las formas de conocimiento y a las técnicas de las que dispone para el diagnóstico de los problemas. Aunque Shore (2010) coincide con este planteamiento al sostener que las políticas públicas habitualmente tienen efectos que se alejan de los propósitos e intenciones de sus arquitectos, sitúa la explicación de este hecho en la compleja red de relaciones en la que estas se insertan una vez que se inicia su proceso de implementación. Las consideraciones de estos autores plantean la necesidad de enfocar el análisis, no tanto en el éxito o fracaso que las políticas puedan tener en el cumplimiento de unos propósitos oficiales, como en los efectos reales que estas producen sobre las poblaciones a las cuales se dirigen. El caso de las politicas agrarias desplegadas por la Caja Agraria y el Incora en el Caquetá es rico en ejemplos que evidencian los efectos no esperados de las intervenciones de desarrollo.

Como se indicó antes, existe un rotundo consenso tanto entre los colonos y ex funcionarios, como entre los analistas, en señalar el fracaso del programa de colonización dirigida adelantado por la Caja Agraria en la región. El origen de este fallido intento de consolidación de las colonias agrícolas puede situarse en la inadecuada planeación del programa que al obedecer a un diseño estandarizado de parcelas geométricas delimitadas con base en los planos de la zona, no tuvo en cuenta las condiciones reales del terreno. Fue así como en el trazado de las parcelaciones se cometieron múltiples fallas, por lo que al momento de la asignación de los lotes muchos adjudicatarios se encontraron con tierras de mala calidad, sin acceso a fuentes de agua o incomunicadas (Brücher, 1974; Gómez, González, Laverde y Torres, 1977; Amézquita, 1981; Marsh, 1983).

También el proceso de selección de los colonos fue errado, ya que el reclutamiento de los mismos se hizo de manera indiscriminada sin tener en cuenta la experiencia previa en las labores agropecuarias como un requisito para poder acceder al programa. Así, la gran mayoría de los colonos desempeñaba oficios urbanos en sus lugares de origen, lo cual hizo sumamente dificil su proceso de adaptación tanto a las condiciones climáticas como a las labores del campo (Gómez, et al., 1977; Amézquita, 1981; Marsh, 1983; Artunduaga, 1984). Manuel, un 
boyacense que tiempo después de haber llegado al Doncello como colono espontáneo, logró vincularse al programa de colonización dirigida en Maguaré, describe esta situación:

Pero cuando eso no venía un trabajador del campo, que supiera empatar un hacha y tumbar un palo, coger un machete, afilarlo pa' rozar, ¡nada!, eran todos empleados de pueblo, peluqueros, sastres, choferes [...] (Manuel, entrevista, Florencia, 19 de julio de 2013)

Los resultados de la intervención de la Caja Agraria en el Caquetá dejan entrever otro rasgo importante a considerar dentro del funcionamiento de las políticas públicas que, lejos de seguir el recorrido lineal representado en diagramas de flujo o en hojas de ruta pulcramente diseñadas, transitan un camino sinuoso en el que la contingencia y la improvisación juegan un papel determinante (Shore, 2010; Gupta, 2012). Un claro ejemplo de cuán desordenada puede ser la implementación de estas políticas son los procesos de selección, traslado e instalación de los colonos dirigidos, quienes tenían que esperar hasta último momento para ser informados sobre los lugares en donde serían ubicados, además de tener que padecer las incomodidades más enojosas durante su traslado.

El proceso de instalación de los colonos no era menos difícil, pues a estos se les asignaba un lote que apenas estaba dotado de un par de mojones y en el que tenían que empezar por levantar un techo en el cual guarecerse de las adversas condiciones del medio selvático. Además se presentaron problemas en la asignación de las parcelas, ya que en ocasiones un mismo terreno era adjudicado a dos colonos simultáneamente, por lo que uno de los dos tenía que ser reubicado perdiendo las mejoras incorporadas al lote. La modalidad de crédito implementada por la entidad tampoco ayudó mucho a consolidar este proceso, pues inicialmente los plazos concedidos para el pago de la deuda fueron demasiado cortos, como insuficientes fueron las reses entregadas a las familias y el monto mismo de los créditos. En conjunto estos factores produjeron la deserción de la mayoría de los beneficiarios del programa. 
Pese a que el Incora obtuvo mejores resultados que la Caja, su intervención no estuvo exenta de efectos inesperados, los cuales pueden explicarse en parte, por algunos errores cometidos en el diseño e implementación de los programas, pero fundamentalmente por el afán de los técnicos de darle cumplimiento a unas metas. Es decir que aunque las intenciones de los funcionarios eran las mejores, muchas veces terminaron anteponiendo la consecución de las metas que les eran asignadas a la pertinencia de los programas para los colonos, cuya opinión no era tenida en cuenta a la hora de planear dichas intervenciones. En palabras de Roberto, que laboró 28 años en el Incora: "Aquí hubo varias cuestiones que fueron impuestas y era necesario imponerlas para poder que se hicieran" (Roberto e Ignacio, entrevista, Florencia, 10 de enero de 2015).

Un ejemplo claro de esta situación está representado en el fomento a la siembra de caucho y palma anteriormente referido. Estos cultivos requieren de un trabajo intensivo, de unos conocimientos específicos sobre su cuidado y de altas inversiones de dinero, condiciones que sumadas a su tardio rendimiento, hacen totalmente inconveniente su siembra en pequeñas parcelas. No obstante el Instituto conminó a los colonos a plantarlos en sus fincas supeditando la entrega de créditos a esta condición. Quienes lo hicieron no contaban con una información adecuada acerca de sus características ni de la manera de aprovecharlos. Es más, de acuerdo con los testimonios de los beneficiarios e incluso, de algunos funcionarios, ni siquiera estos últimos tenían plena seguridad de la viabilidad que estos productos pudieran tener en los suelos amazónicos, pues en cierta forma se encontraban 'experimentando' con ellos, como lo expresó uno de los oficiales entrevistados.

Otra de las líneas productivas promovida por el Incora en la región fue la ganadería cuyo establecimiento fue pensado como una manera de sortear las bajas condiciones de fertilidad de los suelos amazónicos para los cultivos agrícolas, así como de procurarle a los colonos medios de sustento a corto plazo. Aunque el debate conservacionista estaba lejos de aparecer en el ámbito discursivo, no por ello se puede desconocer el impacto ambiental sobre los bosques que el modelo ganadero trajo consigo. Algunos colonos narran cómo a expensas de 
este modelo los funcionarios del Incora promovieron el desmonte de las áreas selváticas.

Además de los fallidos resultados del programa de fomento a la siembra de caucho y palma y de la degradación ambiental ocasionada por el esquema ganadero, otro de los efectos no intencionados de la intervención del Incora en la región fue la expansión del proceso de concentración de la tierra. Con esto no pretendemos afirmar que el Instituto haya sido el único responsable del desarrollo de este proceso en la región, el cual empezó a darse por lo menos un par de décadas antes de la llegada del Instituto al Caquetá, con antecedentes tan importantes como la Hacienda Larandia ${ }^{8}$. Pero tampoco se puede desconocer que al no establecer límites legales al número de hectáreas que podía ser adquirido en tierras privadas ${ }^{9}$, el Incora permitió que el problema de la concentración territorial se extendiera a la frontera tal y como lo evidencian las cifras de catastro regional para el periodo comprendido entre 1967 y 1983 (Serrano, 1994), es decir, prácticamente el mismo periodo abarcado por los proyectos del Instituto.

Los casos analizados aquí son ilustrativos de la manera como las políticas públicas terminan produciendo resultados arbitrarios, como lo comprobó Gupta (2012) en su estudio sobre las burocracias en la India, por cuanto el cumplimiento de las metas de los programas termina imponiéndose sobre la eficacia de los mismos en la resolución de las necesidades de sus beneficiarios, trayendo consigo efectos no deseados como el abandono de las parcelas por parte de los colonos, la dilapidación de los recursos públicos y el deterioro ambiental, o contribuyendo de manera indirecta a la concentración de la tierra. Las palabras de Calixto que estuvo vinculado al Incora

8 En el estudio realizado por Sinchi se indica el rápido proceso de expansión de esta hacienda que en sus inicios en el año de 1935, contaba con 1.794 hectáreas y para mediados de la década de los sesenta había alcanzado una extensión superior a las 35.000 hectáreas e igual número de cabezas de ganado, convirtiéndose de esta manera, en la empresa ganadera más grande del país (Sinchi, 2000)

9 Aunque el Incora limitó el número de hectáreas que un colono podía solicitar para titulación en tierras baldias (450 hectáreas), no estableció tope alguno para la adjudicación de predios en tierras privadas, lo que posibilitó que los acaparadores de tierras que contaban con cierta solvencia económica y que no encontraron límites legales para la adquisición de predios privados, compraran las parcelas desmontadas por los primeros colonos, logrando de esta manera hacerse a grandes extensiones de tierra. 
durante 27 años, son dicientes en este sentido: "había que buscar la posibilidad de cumplir metas, porque si no se cumplian metas pues tampoco $[. .$.$] pues lo iban calificando a uno y de pronto más tarde lo$ despedian" (Calixto, entrevista, Florencia, 19 de julio de 2013).

\section{Consideraciones finales}

En este artículo hemos abordado el caso de las políticas de colonización y desarrollo rural implementadas por la Caja Agraria y el Incora en el piedemonte caqueteño entre 1960 y 1980. Aunque consideradas en conjunto, estas politicas cumplieron con su cometido de extender la soberanía nacional a las zonas de frontera, el análisis de la vida social de estas políticas en una región particular revela los límites de las racionalidades de gobierno para imponer sus fines. En efecto vimos cómo el periodo de este estudio coincide en gran parte con el régimen del Frente Nacional (1958-1974), cuyas diferentes administraciones se dieron a la tarea de extender y consolidar el proyecto de dominación estatal hacia las áreas rurales a partir de una doble estrategia orientada a la pacificación de las zonas de mayor agitación violenta por un lado, y al fortalecimiento del aparato burocrático por el otro. Dentro de esta segunda estrategia, entidades como la Caja Agraria y el Incora jugaron un rol decisivo al posibilitar el ejercicio de un mayor control del Estado en regiones donde su presencia habia sido bastante precaria.

Vistas desde este ángulo, las instituciones de desarrollo y las políticas agenciadas por ellas cumplen una función claramente instrumental en la legitimación del proyecto de dominación estatal. A esto se suma su papel en la construcción de una representación despolitizante de la vida social que a través de prácticas como la problematización y la traducción técnica, terminan removiendo de la esfera del discurso político, cuestiones neurálgicas como la tenencia de la tierra, la ilegitimidad estatal y la pobreza. Pero una aproximación etnográfica al desarrollo de estos programas en contextos locales específicos como el piedemonte caqueteño, permite descubrir la fragilidad de estas racionalidades de gobierno cuyos propósitos no siempre 
se cumplen e incluso, producen efectos imprevistos y adversos. Los casos presentados en este trabajo revelan la brecha existente entre los propósitos oficiales de las políticas y la práctica en sus contextos reales de implementación, en los que la improvisación o el afán de darle cumplimiento a unas metas producen efectos que se alejan en mucho de las intenciones de sus autores. De ahí la necesidad de llevar el análisis más allá de los textos oficiales en los que se sustentan las políticas, para centrarse en la manera como funcionan en la práctica, donde sus efectos inesperados aparecen, no como desviaciones de su diseño inicial, sino como el resultado de la compleja red de actores y de intereses en la que se insertan.

Asimismo, la imagen de las instituciones de desarrollo como entidades monolíticas y todopoderosas que buscan apuntalar un proyecto global de dominación, se desdibuja ante la multiplicidad de intereses y de valores que mueven a sus funcionarios que lejos de tener la intención de servir a las clases en el poder, se involucraron de manera decidida en el trabajo a favor de los más pobres. Convencidos de las bondades de los programas que ejecutaban, los funcionarios de estas entidades tuvieron que sortear toda clase de vicisitudes en el desarrollo de sus labores, las cuales fueron asumidas con un compromiso inquebrantable. No obstante lo anterior, es preciso tomar en consideración el hecho de que muchas veces no bastan las nobles intenciones cuando se privilegia el cumplimiento de unas metas que a la postre, le impiden el acceso de los servicios estatales a los sectores desfavorecidos.

Al mismo tiempo, la mirada de los beneficiarios de estas políticas como agentes pasivos, cuya conducta es moldeada a partir de la imposición de determinadas racionalidades de gobierno, se ve desmentida por la manera como estos las interpelan, resignifican o cuestionan en función de sus propias lógicas y de la posición que ocupan dentro de configuraciones de poder específicas. En este sentido, no se puede asumir de antemano que los programas de desarrollo funcionan sin tener en cuenta las diversas formas sociales que adoptan en los contextos en que son implementados. Es así como algunos beneficiarios desarrollan estrategias creativas que terminan subvirtiendo los fines 
de dichos programas, otros muestran un consentimiento disimulado hacia los proyectos para acceder a sus beneficios, mientras que otros más los impugnan abiertamente.

\section{Referencias}

Agudo, A. (2011). Mejoras privadas, beneficios colectivos: la producción y subversión de regímenes globales de política social en Chiapas. En A. Agudo y M. Estrada (Eds.), (Trans)formaciones del Estado en los Márgenes de Latinoamérica. Imaginarios Alternativos, Aparatos Inacabados y Espacios Transnacionales (pp. 231-283). México: UIA-COLMEX.

Amézquita, C. (1981). Nuevos modelos de vinculación de zonas de colonización a la vida nacional. Tesis de pregrado no publicada. Universidad Nacional de Colombia, Bogotá.

Artunduaga, F. (1984). Historia general del Caquetá. Florencia: Tesoreria Municipal de Florencia, Lotería del Caquetá y Concejo Municipal de El Doncello.

Brücher, W. (1974). La colonización de la selva pluvial en el piedemonte amazónico de Colombia. El territorio comprendido entre el río Ariari y el Ecuador. Bogotá: Instituto Geográfico Agustín Codazzi.

El Espectador (1960, diciembre 14). Más crédito y más plazo piden colonos del Caquetá. Grave situación plantean ante la Cámara. El Espectador, p. 16.

Ferguson, J. (1994). The Anti-politics Machine: "Development", Depoliticization, and Bureaucratic Power in Lesotho. Minneapolis: University of Minnesota Press.

Foucault, M. (2001). El sujeto y el poder. En H. Dreyfous y P. Rabinow, Michel Foucault: Más allá del estructuralismo y la hermenéutica (pp. 241-260). Buenos Aires: Nueva Visión.

Foucault, M. (2006). Seguridad, territorio, población. Buenos Aires: Fondo de Cultura Económica. 
Galli, R. (1978). Rural Development as Social Control: International Agencies and Class Struggle in the Colombian Countryside. Latin American Perspectives, 5(4), 71-89.

Gómez, M., González, J., Laverde, N. y Torres, Z. (1977). Incidencia socioeconómica del Proyecto de colonización del Caquetá Etapa I. Tesis de pregrado no publicada. Universidad Santo Tomás, Bogotá.

Gupta, A. (2012). Red Tape: Bureaucracy, Structural Violence and Power in India. Duke y London: Duke University Press.

Herron, J. (2003). Animating the State: Discourses of Authority and Intimacy in the Colombian Agrarian Bank. Tesis de Doctorado no publicada. University of Michigan, Ann Arbor.

Howard, E. (1976). The approach to Agrarian Reform in Colombia and the Role of the External Lending Agencies. Tesis de Doctorado no publicada. Universidad de Harvard, Cambridge, Massachusetts.

Instituto Amazónico de Investigaciones Científicas (Sinchi) (2000). Caquetá, construcción de un territorio amazónico en el siglo XX. Bogotá: Tercer Mundo Editores.

Instituto Geográfico Agustín Codazzi (IGAC) (1998). Principios básicos de cartografia temática. Bogotá: IGAC

Inda, J. (2005). Analytics of the Modern: An Introduction. En J. Inda (Ed.). Anthropologies of Modernity. Foucault, Governmentality, and Life Politics (pp. 1-20). Malden: Blackwell Publishing.

Jaramillo, J. (1989). Historia y dimensiones socioculturales del proceso colonizador. En J. Jaramillo, L. Mora y F. Cubides, Colonización, coca y guerrilla (pp. 1-130). Bogotá: Alianza Editorial Colombiana.

Li, T. (2007). The Will to Improve. Governmentality, Development and the Practice of Politics. Durham y London: Duke University Press. 
Marsh, R. (1983). Development strategies in rural Colombia. The case of Caquetá. Los Ángeles: University of California.

Mosse, D. (2005/2012). Una etnografia de las políticas de la ayuda en la práctica. En B. Pérez (Ed.), Antropología y desarrollo. Discurso, prácticas y actores (pp. 258-281). Madrid: Los libros de la Catarata, Instituto Universitario de Desarrollo y Cooperación, Universidad Complutense de Madrid.

Serrano, E. (1994). El modelo ganadero de la Gran Hacienda: un paso atrás en el desarrollo del Caquetá. Florencia: Universidad de la Amazonia.

Shore, C. (2010), La antropología y el estudio de la política pública: reflexiones sobre la formulación de las políticas públicas. Revista Antipoda, 10, 21-49.

Shore, C. y Wright, S. (1997). Introduction. En C. Shore y S. Wright (Eds.), Anthropology of Policy: Critical Perspectives on Governance and Power (pp. 3-39). Londres: Routledge.

\section{Cómo citar este artículo}

Martínez, S. P. (2016). Mas allá de la guberbamentalidad: políticas de colonización y desarrollo rural en el piedemonte caqueteño (1960-1980). Universitas Humanística, 82, 135-162. http:/ / dx.doi.org/ 10.11144/Javeriana. uh82.gpcd 